\title{
Health professionals decry detention of migrant children in Canada
}

\author{
n Cite as: CMAJ 2018 July 16;190:E867. doi: 10.1503/cmaj.109-5630
}

Posted on cmajnews.com on June 29, 2018.

M ore than 2000 health professionals and dozens of health organizations are calling on the Canadian government to stop detaining migrant children and families.

"Imprisoning children, or forcibly separating them from their parents, is simply not acceptable, no matter what the migratory status of the children or their parents," they urged in an open letter to the ministers of health, public safety and immigration.

In general, however, children are not separated from their families in Canada, according to Hanna Gros, a senior fellow with the University of Toronto's International Human Rights Program and author of a paper on this subject. "We don't detain children en masse and we don't have family separation en masse," Gros told CTV News. "But that doesn't mean that there are no human rights violations being committed in the context of Canadian immigration detention."

Canada has held some 45000 migrants in detention over the past six years. Last year, 162 children were detained with parents or guardians in facilities, some that resemble medium security prisons.

"They are not by definition jails, but they are jail-like," said Dr. Michaela Beder, a Toronto psychiatrist who works with migrants in detention.

"The mental health impacts of immigration detention are severe," said Beder, who helped draft the open letter. After even a short time, both children and adults can suffer increased symptoms of depression, anxiety and post-traumatic stress. Children may have trouble eating and sleeping, and suffer delays in their development, in some cases losing the ability to speak.

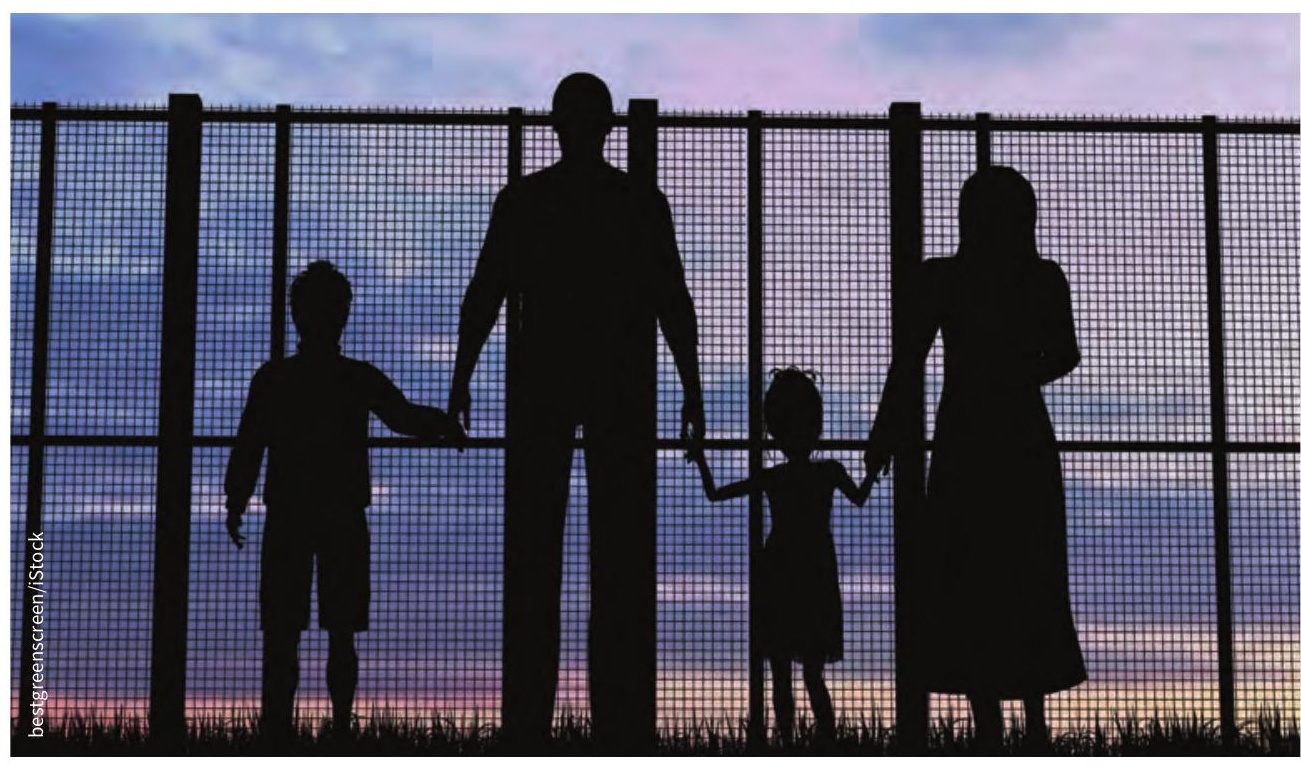

Migrant children and families face serious mental health harm in "jail-like" holding facilities, says Toronto psychiatrist.

Because there's no legal limit on the length of detention, "people become really, really distressed," said Beder. "The fact that it's indefinite is so traumatizing and unsettling."

The open letter urges the federal government to end child detention, but also immigration detention in general. According to a 2015 report by the International Detention Coalition, there are more than 250 alternative approaches used around the world that are more humane, less expensive and equally effective.

In November 2017, Public Safety Minister Ralph Goodale directed border services to keep children out of detention and allow families to stay together as much as possible. "The concern is that it's just a policy and people can still be detained indefinitely," said Beder. "That's why we need a legislated maximum length of detention and have to look at a much broader systemic solution."
The open letter also calls on Canada to end the Safe Third Country Agreement, which prevents migrants from claiming refugee status in Canada if they're entering via the United States. The rule presumes that the US is an equally safe country for refugees. According to the open letter, that's no longer the case given the Trump administration's increasing hostility toward migrants, whom the president recently labelled as "invaders."

"People are literally being imprisoned when they come to seek asylum and separated from their children with no sense of when they'll be reunited," said Beder.

More than 30 health organizations cosigned the open letter, including the Canadian Paediatric Society, Canadian Association of Community Health Centres, and the Canadian Federation of Medical Students.

Lauren Vogel, CMAJ 